\title{
PENÍNSULA, LOS PRIMEROS PASOS
}

Mario Humberto Ruz

editor de 2005 a 2012

Centro de Estudios Mayas, IIfL, UNAM

Si bien vio la primera luz en Mérida el 16 de diciembre de 2005, Península, como cualquier nuevo miembro de familia respetable, fue concebida en París. Desde allí fue planteada como una de las acciones a emprender en la Unidad Académica de Ciencias Sociales y Humanidades, cuya dirección me fue encargada en julio de ese año por el entonces rector de la UNAM, Juan Ramón de la Fuente. Una vez aceptada la propuesta por el rector, la coordinadora de Humanidades, Maricarmen Serra Puche y, primordialmente, por los propios académicos de la UACshum, Península pasaría a convertirse en el órgano oficial de esa dependencia universitaria y de su hoy sucesor, el Centro Peninsular en Humanidades y en Ciencias Sociales (CEPHCIS), creado por acuerdo del Consejo Universitario el 17 de agosto de 2007.

Desde sus inicios la revista se planeó como una ventana donde dar a conocer los resultados de las investigaciones desarrolladas en la sede de la UNAM en Mérida, pero no sólo de ella; se concibió como un espacio abierto a las contribuciones de colegas de otras entidades académicas ya fuera que trabajasen sobre la península de Yucatán o acerca de otras temáticas y latitudes, como corresponde a la universalidad del conocimiento y su difusión. Una revista, pues, regional por su factura, pero distante de chatos regionalismos en sus contenidos.

Muestra de su impronta regional fue el diseño de la portada misma, que propuse diera cuenta estilizada de la división peninsular en tres estados, quedando la cartela a manera de indicador de la frontera del Río Hondo (una propuesta que Samuel Flores Osorio plasmó con el buen gusto que le caracteriza); muestra de su vocación pluridisciplinaria fue el que optase por albergar, entre otros, textos de antropología física, antropología social, ecología, economía, etnología, filología, filosofía, geografía, historia, lingüística, literatura, pedagogía y sociología. Una variedad disciplinar que refleja el espíritu abierto y plural que alienta a la UNAM, y que en diversos momentos se ha hecho presente en la sede de Mérida.

Asegurar la periodicidad de la revista nos pareció punto de particular importancia. Laborando de manera intensiva con el Comité Editorial, conformado por colegas que generosamente aportaron su tiempo y capacidad, se logró que los catorce volúmenes a cargo de la última administración de la UACSHUM y la primera 
del CePHCis cumplieran durante siete años con la periodicidad semestral comprometida. El último de tales números, el primero del volumen VII, terminó de editarse el 20 de octubre y en el colofón ostenta como fecha de impresión el 10 de noviembre de 2012, justo cinco días antes de iniciarse el proceso de cambio en la conducción del Centro. ${ }^{1}$

Me parece de interés destacar lo anterior ya que, como bien sabe cualquiera que se haya dado a la tarea de editar una revista semestral desde la provincia mexicana, lejos de los centros tradicionales de difusión del quehacer humanístico y científico, mantener su periodicidad no siempre resulta tarea sencilla, en especial cuando no se cuenta con un equipo dedicado específicamente a ello, ${ }^{2}$ pero por fortuna no escasearon las propuestas de los colegas, tanto nacionales como extranjeros, alentados sin duda por el hecho de tratarse de una revista de la UNAM, avalada por la indiscutible calidad académica de los integrantes de su Consejo Editorial, la seriedad de los procesos de evaluación y el reconocimiento implícito a su calidad que significó su incorporación a índices como Latindex en 2008, la base de datos CLASE en marzo de 2009 y, el 27 de octubre de ese mismo ańo, scielo, lo que da cuenta del prestigio que la revista fue logrando en el medio académico.

Los resultados cuantitativos son reveladores, pues la catorcena de números mencionados significó la publicación de más de setenta artículos originales en español, maya e inglés, así como reseñas, pero mucho más trascendental que ello son sin duda la calidad académica y la variedad disciplinaria de que dan cuenta tales textos.

Así, en los números publicados durante esa que podríamos considerar "primera época" de la revista, es posible encontrar testimonios de los avances registrados en investigaciones sobre la región, entendida ésta como un proceso en continua construcción, tanto como otros que dan cuenta de territorialidades y espacios disciplinares más amplios.

Lo relativo al ámbito peninsular, numéricamente lo más abundante, incluye ensayos de corte histórico con un amplio abanico de temáticas donde tienen cabida estudios sobre patrimonio material, coleccionismo arqueológico, organización familiar, economía de las haciendas, evangelización y control eclesiástico; saberes, prácticas y agentes terapéuticos mayas; delimitación territorial e ideológica de las fronteras peninsulares y los consecuentes impulsos colonizadores, así como acerca de los afanes separatistas yucatecos; el conflicto armado con buena parte de la población maya; el papel jugado por la prensa en la construcción del regionalismo peninsular o la llegada de grupos de inmigrantes desde el Viejo Mundo.

Por lo que toca a temáticas contemporáneas, pueden encontrarse estudios sobre la construcción y crecimiento del espacio metropolitano centrado en Mérida,

\footnotetext{
${ }^{1}$ En enero de 2013 se entregaron al titular designado los textos que se encontraban en proceso de evaluación, a fin de que los nuevos responsables de la revista diesen seguimiento a su eventual publicación. Algunos de ellos aparecieron en los dos números siguientes.

2 En ese entonces los dos editores nos encargábamos desde la solicitud de contribuciones y su envío a dictamen, hasta la corrección de estilo y la revisión ortotipográfica de cada una de las pruebas de imprenta.
} 
incluyendo reflexiones de tono sociológico sobre las trayectorias de ascenso social de los mayas residentes en esa ciudad, las agendas gubernamentales de desarrollo, el ecoturismo o el impacto del discurso publicitario en las actitudes suicidas, entre otros temas. A la par, se aprecian valiosos aportes de orden antropológico y etnográfico, que atienden a la casa maya considerada "tradicional", las actividades de cacería, las prácticas religiosas familiares y comunales, el culto a los antepasados, tal o cual sistema terapéutico, y ensayos acerca de marcadores identitarios tenidos por esenciales como el vestido y la lengua, área esta última que ha prestado atención a aspectos fonológicos, sintácticos y determinadas variaciones dialectales del maya yucateco; tema de enorme trascendencia en la región, de clara impronta mesoamericana.

Lo vinculado al ámbito maya rebasa el territorio de la península a través de artículos dedicados a expresiones socioculturales en regiones vecinas como Tabasco, Chiapas y Guatemala, o incluso distantes como la Huaxteca, a más de contribuciones que, desde perspectivas epigráficas, arqueológicas, iconográficas, históricas e incluso ecológicas, aportan reflexiones comparativas sobre manifestaciones culturales en diversos pueblos de filiación etnolingüística maya.

Acorde con lo señalado en el decreto de creación de la sede que la alberga, Peninsula buscó desde un inicio dar cuenta también de estudios relativos al área centroamericana. Así, figuran en los números aquí tratados ensayos sobre la disputa anglo-hispana por los espacios caribeños, actividades productivas y comerciales en la región mam, o acerca de la difícil situación femenina en la Guatemala colonial, que se percibe a través de correspondencia privada y juicios públicos, a más de una serie de contribuciones que abordan aspectos socio-religiosos, desde rituales del Clásico Terminal en el Petén, hasta la manera en que la conversión al pentecostalismo impacta la cosmovisión maya, pasando por la religiosidad indígena en la Guatemala dieciochesca, la que caracteriza hoy a ciertos grupos de mestizos que veneran a la virgen de Guadalupe, o el papel que juegan los maestros de coro de algunos poblados chujes (asentados en el área montañosa de los Cuchumatanes), en el mantenimiento de determinados referentes identitarios. Procesos todos ellos que vinculan la religiosidad con la conformación o reconfiguración de espacios políticos, económicos y sociales.

Otra muestra del interés en procesos ocurridos más allá de los límites peninsulares son varios ensayos, de naturaleza tan diversa como complementaria, que dan cuenta de regiones fronterizas, ya del meridión, ya del septentrión nacionales, bien aproximándose a las serranías y planicies tabasqueñas (colindantes con Guatemala), bien a los seris de Sonora, bien historiando la difícil situación que enfrentaron sucesivamente durante siglo y medio los linderos norteños de la Nueva España y México por los afanes expansionistas de los ingleses.

Puesto que, por naturaleza, las Humanidades y las Ciencias Sociales extienden su quehacer más allá de territorios geográficos constreñidos y circunscritos, no es de extrañar que en las páginas de la revista sea factible encontrar consideraciones 
acerca de temáticas más amplias. Ejemplo de ello son los ensayos acerca de las letras en el barroco hispanoamericano vistas desde la polémica hispano-criolla, la correspondencia amorosa privada en Yucatán y Guatemala, el análisis de diarios de expedición en el Virreinato de la Nueva Espańa y los reportes de viajeros en la provincia del Río de La Plata, las revistas literarias decimonónicas, la narrativa hispanoamericana sobre los piratas del Caribe o la recepción inicial que tuvieron obras polémicas como la de José Revueltas hace medio siglo.

A la par, la reflexión filosófica se hace presente con textos sobre la obra de Descartes y Kant o que se detienen en autores como Sade, Maupassant y Barthes, junto a otros dedicados a los procesos de socialización del conocimiento, la conciencia y pensamientos de nivel superior o la autoconciencia y la identidad personal, que puede palparse incluso en hechos tan cotidianos como los que afectan a un pescador de la costa yucateca que, empujado por los programas gubernamentales de supuesto desarrollo regional, se ve obligado a convertirse en piscicultor.

Dar cuenta de todo ello, con calidad y eficiencia, no hubiese sido posible sin el apoyo de los investigadores de la sede y otros colegas que nos confiaron sus textos, y la generosa labor del pequeño equipo que tuvo a su cargo la revista en esos primeros siete ańos; equipo conformado primordialmente por Daniela Maldonado Cano como coeditora, Norma Cano Yebra y Marcos García Yeh como sucesivos formadores y Samuel Flores Osorio como diseñador, a más de aquellos otros que fungieron como editores responsables de algunos números o apoyaron diversas labores, incluyendo las administrativas. La suma de todos estos esfuerzos, calidades y voluntades, hizo factible que la revista se fuera consolidando como un espacio de exposición y reflexión académicamente calificado, a más de atractivo, de particular valía en el entorno regional y más allá. Justo es, pues, agradecer a todos ellos su entusiasmo, confianza y empeño ahora que Peninsula cumple medio katún de una existencia que se augura incluso más promisoria. 